\title{
Addressing the tacit knowledge gap in knowledge systems across agential realism
}

\author{
W. David Holford \\ University of Quebec at \\ Montreal (UQAM) \\ Holford.w_david@uqam.ca
}

\author{
Pierre Hadaya \\ University of Quebec at \\ Montreal (UQAM) \\ Hadaya.pierre@uqam.ca
}

\begin{abstract}
Past literature has claimed that knowledge systems can enhance or facilitate the creation, retention, transfer and application of tacit knowledge. While this paper agrees that this objective is realizable, it argues that the literature has so far failed to successfully operationalize this, since at the core of the models published to date lies the flawed epistemological assumption of knowledge 'conversion' - more specifically, tacit to explicit knowledge conversion.

This paper proposes the alternative epistemology of agential realism which allows us to reframe tacit knowledge within knowledge systems, whereby humans and machine are coupled together (intra-act) to enhance and retain tacit knowledge creation and sharing without putting undue emphasis on its conversion and storability into an explicit form - thus, agential realism allows tacit to remain as tacit. In addition, this critical-conceptual paper proposes nascent examples of human-machine or knowledge system configurations which have affinities or potential affinities with an agential realist approach.
\end{abstract}

\section{Introduction}

Past literature has acknowledged the importance of tacit knowledge, whereby it has often been associated to expert know-how and 'deep smarts' [1, 2, 3, 4]. For example, Collins [3] refers to a specific aspect of high level expert knowledge which he coins as collective (or deep) tacit knowledge residing within social groups (and more specifically, communities of practice). Such knowledge goes beyond knowledge of past situations in that it involves flawless improvisation to address current situations at hand. Attaining such knowledge involves social embedding or social immersion in the specific social settings of the communities of practice in question. Examples range from the more taken-forgranted bike-riding in traffic [5] to dynamic and knowledge intensive examples such as multi- disciplinary surgery teams dealing with non-typical situations [6, 7]. Along similar lines, Leonard and Swap [4] argue that deep knowledge (or "deep smarts") which certain experts possess, that is something experts are especially good at after many years of experience, involves significant levels of tacit knowledge in the form of know-how and know-who which cannot be easily documented because of its highly contextual nature as well as in its difficulty to fully explicate. Here, the authors refer to the ability to reason swiftly without much conscious effort yet able to identify trends and anomalies which would escape the notice of less experienced individuals. When asked to explain a specific decision, "experts often cannot recreate all the pathways their brains checked out and so cannot give a carefully reasoned answer" $[4$, p. 6].

Despite the non-representational character of such knowledge, it has been argued that various knowledge system technologies and techniques can enhance or facilitate the creation, retention, transfer and application of tacit knowledge [8, 9, 10]. More specifically, it is viewed that information and communication technologies (ICT) such as e-learning technologies and techniques can help transform or convert tacit knowledge into explicit knowledge [9]. In a more global fashion, Selamat and Choudrie [8] propose an Information Systems (IS) framework to convert and codify tacit knowledge into explicit knowledge. Along similar lines, Alavi and Leidner [10] had proposed a 4-step framework of knowledge creation, storage, transfer and application. In all cases, Nonaka and Takeuchi's [11] knowledge creation model is referred to in regards to converting tacit knowledge into explicit knowledge.

While this paper agrees that knowledge systems can most certainly enhance or facilitate the creation, retention, transfer and application of tacit knowledge residing within individuals and groups, we argue that current approaches may be flawed in two interconnected manners:

1. The assumption that embodied tacit knowledge can be retained via its 'conversion' to explicit knowledge and subsequently stored in traditional 
manners, such as documentation and codification is highly questionable.

2. The lack of understanding of what indeed we are trying to retain, transfer and apply when we refer to tacit knowledge.

Inspiring ourselves with the work of various authors, including Collins [3], Tsoukas [12] and Carter et al [13], we will first present our position as to what tacit knowledge is and is not, and as such, argue that deep high-level tacit knowledge cannot be 'converted' and dissected into language or code, but at best only partially explicated in terms of equivalent (yet not identical to tacit) descriptions. We will then propose an approach based on Karen Barad's [14] ontoepistemology of agential realism, which we argue is more in line with the view of the deep, highly inextricable, distributive and hard to explicate nature of collective tacit knowledge residing within communities of practice. Across this alternative lens we also briefly propose possible ways forward that can constructively couple humans and machines (or information and communication technologies) and thus allow for the sharing and transfer of tacit knowledge within a more non-dichotomous human-machine knowledge system.

\section{Understanding tacit knowledge}

Polanyi first introduced the terms tacit knowledge and tacit knowing in his work on Personal Knowledge [15]. For Polanyi [15], tacit knowledge cannot be adequately articulated by verbal means which he later summarized as "we know more than we can tell" [16, p. 4]. Yet, in-line with Polanyi, Tsoukas [12, p. 424425] states:

The ineffability of tacit knowledge does not mean that we cannot discuss the skilled performances in which we are involved...provided we stop insisting on "converting" tacit knowledge and, instead, start recursively drawing our attention to how we draw each other's attention to things... We can command a clearer view of our tasks at hand if we "remind" ourselves of how we do things so that distinctions which we had previously not noticed, and features which had previously escaped our attention, may be brought forward...we do not so much need to operationalise tacit knowledge as to find new ways of talking, fresh forms of interacting, and novel ways of distinguishing and connecting. Tacit knowledge cannot be "captured", "translated", or "converted" but only displayed, manifested, in what we do. New knowledge comes about not when the tacit becomes explicit, but when our skilled performance - our praxis - is punctuated in new ways through social interaction".

For Polanyi, "all knowing... is personal knowing participation through indwelling" [17, p. 44] which involves skillful action and a "personal coefficient" $[18$, p. 17]. Furthermore, "the aim of a skilful performance is achieved by the observance of a set of rules which are not known as such to the person following them" [18, p. 49]. Or as Tsoukas [12, p. 414] explains, "a cyclist, for example, does not normally know the rule that keeps her balance, nor does a swimmer know what keeps him afloat. Interestingly, such ignorance is hardly detrimental to their effective carrying out of their respective tasks".

In Polanyi's theory [18] tacit and explicit knowledge are related to two types of awareness, namely, subsidiary awareness and focal awareness respectively. For example, in using a hammer to drive a nail, driving the nail down is the focal object of attention. At the same time, one is also aware of subsidiary feelings in the palm of holding the hammer. Hence, the focal object is always identifiable and in this sense explicit, whereas the subsidiary content is unidentifiable or tacit [17]. Furthermore, the two kinds of awareness are mutually exclusive [18, p. 56]; that is, when the attention is switched to something hitherto subsidiary, it becomes focal losing its subsidiary meaning ([19]; [12]). As Tsoukas [12, p. 415] points out, "if a pianist shifts her attention from the piece she is playing to how she moves her fingers...or if a carpenter shifts his attention from hitting the nail to holding the hammer, they will all be confused...In the context of carrying out a specific task, we come to know a set of particulars without being able to identify them, [hence] Polanyi's [16, p. 4] memorable phrase, "we can know more than we can tell"".

Polanyi explains how in the act of acquiring more knowledge (i.e. knowing), the shrinking of consciousness of certain things is, in the context of action, accompanied with the expansion of consciousness of other things. "This lapse into unconsciousness", remarks Polanyi [18, p. 62], "is accompanied by a newly acquired consciousness of the experiences in question, on the operational plane... it is a structural change achieved by a repeated mental effort aiming at the instrumentalization of certain things and actions in the service of some purpose". Polanyi gives the example of a medical student learning X-ray diagnosis of pulmonary diseases. Initially: "he can see in the X-ray picture of a chest only the shadows of the heart and the ribs...The experts seem to be romancing about figments of their imagination; he can see nothing that they are talking about" [18, p. 101]. Eventually however, "he will gradually forget about the ribs and begin to see the 
lungs. And eventually, if he perseveres intelligently, a rich panorama of significant details will be revealed to him: of physiological variations and pathological changes...He has entered a new world" [18, p. 101]. As Tsoukas [12, p. 418] summarizes, "knowledge has, therefore, a recursive form: given a certain context, we blackbox - assimilate, interiorise, instrumentalise certain things in order to concentrate, focus on others".

Nonaka and Takeuchi ([11] p. 61), who were instrumental in popularizing the concept of tacit knowledge in management studies during the 1990's, aptly describe tacit knowledge and explicit knowledge as inseparable from one another: "tacit knowledge and explicit knowledge are not totally separate but mutually complementary entities". This is in line with Polanyi's ([16], p. 195) own words "all knowledge is either tacit or rooted in tacit knowledge". Yet as previously explained, they are also mutually exclusive [18]. These two important points of inseparable yet mutually exclusive entities, would seem to be paraphrased across Nonaka, Toyama and Konno's ([20], p.8) words of "explicit knowledge without tacit insight quickly loses its meaning". Later literature by Nonaka et al ([21], [22]) especially stress the inseparable aspect of tacit and explicit knowledge: "tacit and explicit should not be treated as separate entities but rather mutually complementary and based on the same continuum" ([22], p. 640). The latest literature by Nonaka et al ([23]), again re-illustrates the inseparable aspect of tacit and explicit qualities across organizational 'fractals' consisting of triads of tacit and explicit knowing (with its synthesis forming the third 'pole').

\subsection{Can it be converted to explicit knowledge?}

Past literature has highlighted the debate on tacit knowledge and its relationship with explicit knowledge. According to Nonaka and Takeuchi [11], knowledge is created and expanded through social interaction between tacit knowledge and explicit, whereby "the explanation of how Japanese companies create new knowledge boils down to the conversion of tacit knowledge to explicit knowledge" [11, p. 12]. Along these lines, "for tacit knowledge to be communicated and shared within the organization, it has to be converted into words or numbers that anyone can understand. It is precisely during this time that conversion takes place-from tacit to explicit, and, as we shall see, back again into tacit - that organizational knowledge is created" [1, p. 9)].

Numerous authors have objected with this view [3. 4, 12, 13]. For example, Carter et al [13, p. 62] state "short of a brain transplant, the capacity to know [(tacit knowledge)] is not a transferable commodity".
Virtanen's [19] pertinent analysis of tacit knowledge argues that while Nonaka et al's ([21], [22]) description of a knowledge continuum ranging from 'almost' wholly explicit knowledge at one end to 'almost' fully tacit knowledge on the other end, offers a useful analogy depicting both the inseparable qualities and changing degrees of tacit and explicit knowledge, the concept of 'knowledge conversion' of tacit to explicit when going along this continuum becomes highly problematic in terms of what indeed is meant and how this is interpreted. Beyond Nonaka et al's ([21], p. 19) attempt to clarify by stating that "the term 'conversion' might be misunderstood as implying that knowledge is a substance that can be processed in the way as physical resources", one is left without much else. Virtanen ([19], p. 122) goes on to argue that the conversion of tacit knowledge to explicit knowledge according to Nonaka and Takeuchi's concept (and as as understood by various other authors such as Hall and Andriani, [24], etc.) involves going from personal beliefs to an objective ideal of knowledge which "Polanyi wanted to criticize with the concept of tacit knowledge".

Tsoukas [12, p. 424] points to a similar issue namely, on whether tacit knowledge can in fact be partially or wholly reduced into articulable language or code, given enough time and effort: "Nonaka and Takeuchi's interpretation of tacit knowledge as knowledge not-yet-articulated - knowledge awaiting for its "translation" or "conversion" into explicit knowledge -, an interpretation that has been widely adopted in management studies, is erroneous: it ignores the essential ineffability of tacit knowledge, thus reducing it to what can be articulated". In a similar fashion, Collins [3, p. 3], argues "Nonaka and Takeuchi describe the way the previously tacit knowledge associated with kneading dough for bread was elicited and formulated so that it could be reproduced in mechanical form in a bread-making machine... They think the notion of tacit knowledge is exhausted by knowledge that just happens not to have been explicated but could be given a bit more effort". More cogently, and similarly argued by Virtanen [19] "the conduit metaphor of communication that underlies Nonaka and Takeuchi's perspective - the view of ideas as objects which can be extracted from people and transmitted to others over a conduit - reduces practical knowledge to technical knowledge... To treat practical (or tacit) knowledge as having a precisely definable content, which is initially located in the head of the practitioner and then "translated"' [11, p. 105] into explicit knowledge, is to reduce what is known to what is articulable, thus impoverishing the notion of practical knowledge. As Oakeshott [25, p. 15] remarks, "a pianist acquires artistry as well as technique..." [12, 
p. 421-422]. This latter point, overlaps onto a second key issue, namely on knowledge involving subjective or personal interpretations: "Nonaka and Takeuchi suggest that the unique can become 'universal'...In Nonaka and Takeuchi's model, explicit knowledge is portrayed as a language of fixed meanings. But neither 'apple', nor any other word, can account for its own interpretation: what a word means cannot be separated from the way in which it is interpreted, which is always subjective" [26, p. 173 and 175].

It should be noted that a later portrayal by Nonaka et al ([23], p. 3 and 4) of the organization in terms of 'fractals' of knowledge triads (tacit knowledge, explicit knowledge and its synthesis leading to 'practical wisdom') across the firm, still does not preclude the questionable notion of conversion if we read words such as "when an individual's tacit knowledge is shared with another person it becomes explicit knowledge, and when this is merged with other explicit knowledge it becomes new explicit knowledge, which in turn can then be converted into the tacit knowledge of an(other or the same) individual" and "In cases like the Toyota Prius, it is clearly shown that tacit knowledge is shared and converted into explicit knowledge".

The next two short sub-sections attempt to further argue that:

1. Knowledge involves personal constructions, thus reminding us that any explication of tacit knowledge is at best a personal and subjective endeavor.

2. Tacit knowledge cannot be wholly reduced into explicit knowledge, and furthermore, what is actually rendered explicit does not always have anything to do with what is actually embodied in the bearer.

\subsubsection{Knowledge as personal construction.} Glasersfeld [27] as well as Ray and Clegg's [26] nonrepresentational view of knowledge construction, begins with Polanyi's own position on knowing “... the capacity to know is personal. Knowledge (no matter how 'knowledge' is defined) is in the heads of persons and the knowing subject has no alternative other than to construct what he or she knows using his or her experience" [26 citing 22, p. 1]. Glasersfeld [27] directly addresses the representational claim of observer objectivity by first explaining, across Jean Piaget's work on cognitive development, how human mental operations lead up towards a mental/subjective construction of reality. These operations involve both the construction of action and symbolic schemes (the latter as interpretive semantics) leading towards sensorimotor and conceptual knowledge, respectively $[27$, p. 76]. Each of these schemes is constructed based on unique personal experiences, which may be similar, but never identical to, another person's constructions [27, p. 158]." The point here is that humans learn by constructing a viable picture of reality; and that we may on occasion 'bump' into our external reality across "failures" [27, p. 156]. This rejoins Weick's [28] theory of individual and organizational sensemaking, which seeks plausibility as opposed to what is true in the absolute sense. As Glasersfeld [27, p. 156] adds, "the idea of correspondence with reality is replaced with the idea of fit. Knowledge is good knowledge if it fits within the constraints of experiential reality and does not collide with them. This fit...has to remain viable in the face of new experience or experiments, but also in that they prove compatible with other schemes and theories one is using".

2.1.2. Collins' Weak, Medium and Strong Tacit Knowledge. Collins [3] explains that tacit knowledge can be divided into three forms: relational, somatic and collective - which can also be thought of as weak, medium and strong tacit knowledge. On the one hand relational 'tacit' knowledge can (with some effort) "be rendered explicit", while at the other extremity, collective tacit knowledge is impossible to fully explicate in that "we know of no way to describe it" [3, p. 11] - but said another way: certain 'weak' dimensions of tacit knowledge can be partially explicated. Yet, the term 'explication' should not be misconstrued as 'conversion'.

The first type being relational or weak tacit knowledge "has to do with the relations between people that arise out of the nature of social life. As Collins [3, p. 11] explains, "a characteristic of weak tacit knowledge is that, in principle, with enough effort, any piece of it could be rendered explicit". Relational tacit knowledge is that which occurs between the professor of kinetics and his physics students. What has become evident for the professor requires an effort of explicitation for the junior physics students.

The second category is what Collins [3, p. 11] calls somatic or medium tacit knowledge "that is knowledge that is tacit because of the way it is inscribed in the material of body and brain". Somatic tacit knowledge is learned progressively and is put in practice in a more or less conscious manner. It is a "knowledge that can be written out but cannot be used by humans because of the limits of their bodies". Bicycle riding/balancing, typing or playing the piano at a highly proficient level, etc. all fall within this category, whereby the knowledge required can be fully explicated, but only as an "expressed scientific understanding of causal 
sequences...and in principle, if not in practice, these can be understood scientifically...how we might go about it though remains technically beyond our [body/brain] capacities" [3, p. 117]. It is often represented by the emblematic case of the case of the artisan baker or breadmaker as described by Nonaka [11] that subsequently became world famous at about the same time that bread-making machines (domestic, etc.) were being developed and diffused.

And finally, there is the strong or collective tacit knowledge "that the individual can acquire only by being embedded in society. This is called "strong", because we know of no way to [fully] describe it or to make machines...even mimic it. Strong tacit knowledge is a property of society rather than the individual" [3, p. 11]. Hence, the individual can learn the practices and language only across a certain degree of social engagement. Collective tacit knowledge resides within the collectivity, for example that which is formed by urban Chinese, Parisians or Londoners. This location can seem paradoxical at first glance, yet less so when we allow for the role of language. Its transmission from one source of generation to another is simultaneously a transmission of knowledge. Riding a bicycle within a specific agglomeration is not just a question of maintaining one's balance on two wheels, but also to understand a set of signs and situations validated by a socialisation process which passes by the mediation of language [3]. Collins [3] also associates this type of knowledge with high level specialised knowledge within a community of practice whereby language and practice can only be fully understood by an outsider via practice and immersion.

\section{The incommensurability of embodied action-oriented tacit knowledge with explicit knowledge}

From the previous section it can be argued that codifying and/or documenting tacit knowledge becomes a problematic, if not impossible, endeavor. Four issues come to mind:

a. Knowledge possessed and carried out by experts in the form of tacit knowledge cannot be fully expressed as language or code

b. Certain aspects can indeed be explicated in the form of code or language may have little to do with the original tacit knowledge in question (ex. equations used as an equivalent, yet not identical, form of knowledge to explain the act of riding a bicycle [29]) c. Knowledge as expressed by individuals or groups involves an endless process of re-construction and interpretation $[27,28]$.

d. High level collective tacit knowledge within groups or communities of practice is distributive in nature - that is, no one individual can possess it all $[2,3]$.

These four issues bring forth two inter-related challenges which have a direct impact on the ability, and thus validity, of capturing such tacit knowledge across mere documentation and/or codification: 1) the clearly flawed assumption of knowledge 'convertability', and 2) the lack of appropriate understanding as to the nature of the knowledge in question that we are trying to capture when we refer to tacit knowledge.

The highly embodied nature of both collective and somatic tacit knowledge cannot be fully extracted (if at all) by a simple act of disembodiment. Several arguments to support this position have already been put forward in the previous sections, yet perhaps one that should be further highlighted is that by Tsoukas [12] when examining the difference between explicit and tacit knowledge. Contrary to explicit knowledge, the highly personal indwelling and contextualized nature of tacit knowledge renders its reversibility (via reproducibility and standardization) impossible [12]. Towards this argument is a first reminder of how knowledge is embodied: "insofar as our contact with the world necessarily involves our somatic equipment - "the trained delicacy of eye, ear, and touch" [17, p. 31] - we are engaged in the art of establishing a correspondence between the explicit formulations of our formal representations (be they maps, scientific laws or organizational rules) and the actual experience of our senses" [12, p. 413-414]. Tsoukas [12, p. 415416] uses Polanyi's subsidiary and focal awareness to explain how the irreversible nature of tacit knowledge cannot be reduced into explicit knowledge (and therefore reversible form) across explanatory articulations unless we strip all meaningful situational elements and actions: "tacit knowledge forms a triangle, at the three corners of which are the subsidiary particulars, the focal target, and the knower who links the two ... No knowledge is possible without the integration of the subsidiaries to the focal target by a person. However, unlike explicit inference, such integration is essentially tacit and irreversible...its irreversible character can be seen if juxtaposed to explicit (deductive) inference...When, for example, you examine a legal syllogism or a mathematical proof you proceed orderly from the premises...to the conclusions. You lose nothing and you recover nothing 
- there is complete reversibility...Such reversibility is not, however, possible with tacit integration. Shifting attention to subsidiary particulars entails the loss of the skillful engagement with the activity at hand. By focussing on a subsidiary constituent of skilful action one changes the character of the activity one is involved with." [12, p. 415-416].

\subsection{Addressing embodied knowledge across agential realism}

The embodied nature of tacit knowledge brings forth two important features: that of integration within the body and that of action. The notion of embodied knowledge is in fact derived from the phenomenology of Merleau-Ponty [30, p. 144]:

To know how to touch type is not, then, to know the place of each letter among the keys, nor even to have acquired a conditioned reflex for each one, which is set in motion by the letter as it comes before our eye. If habit is neither a form of knowledge nor an involuntary action, what then is it? It is knowledge in the hands, which is forthcoming only when bodily effort is made, and cannot be formulated in detachment from that effort.

Merleau-Ponty also explains that in experiences of bodies in situations it is impossible to disentangle so called 'natural' and 'social' elements: "everything is both manufactured and natural in man, as it were, in the sense that there is not a word, not a form of behaviour which does not owe something to purely biological being - and which at the same time does not elude the simplicity of animal life" [30, p. 189].

The natural and the social is again taken up by Latour's [31] non-dualist philosophy of hybridized categories within his concept of actor-network theory. The ideas of Latour and Merleau-Ponty in terms of the non-dual relationship between the natural and the manufactured, as well as the human and the nonhuman, has been more recently reflected within the performativity concept of socio-materiality "there is no social that is not also material, and no material that is not also social" [32, p. 29]. Yet, at the base of Orlikowski's socio-materiality lies a more detailed and exhaustive epistemology (or onto-epistemology) which more fully defines and describes the role and importance of phenomenon within everyday reality, based on the work of Karen Barad [14], known as agential realism. Influential in the development of agential realism was Niels Bohr, a quantum physicist who asserted that observing apparatuses are not merely passive instruments, but things that participate in the formulation of scientific observation, thus challenging the separateness of observer and object. According to
Barad, reality is viewed as a collection of phenomena involving the intra-action between agencies of observation and 'objects' (where both involve shifting boundaries or 'cuts'). Barad [14, p. 104] identifies phenomena as the smallest unit for this intra-action and thus the building blocks for reality, which "is not composed of things-in-themselves or things-behindphenomena, but things-in-phenomena." Phenomena represent the inseparability of an object and observations of it. It also connotes a dynamic quality, and thus, in combination with agency, implies action, or more specifically, intra-action. Central, then, to Karen Barad's [14, p. 49] proposal of a sociomaterial, performative understanding of scientific practices, is "that knowing does not come from standing at a distance and representing but rather from a direct material engagement with the world". As Barad [14, p. 157] points out, “...we do not see merely with our eyes. Interacting with (or rather, intra-acting 'with' and as a part of) the world is part and parcel of seeing. Objects are not already there; they emerge through specific practices". Humans too are constituted through relations of materiality — bodies, clothes, food, devices, tools, which, again, are produced through human practices. "Whereas the construct of interaction suggests two entities, given in advance, that come together and engage in some kind of exchange, intraaction underscores the sense in which subjects and objects emerge through their encounters with each other" (cited in [33, p.267]). And it is in this sense that our 'seeing' things, 'hearing' things, 'making sense' and 'talking of' things, are all material practices, involving the intra-twining, or the entanglement, of certain of our material bodily processes with those of the material world. This entanglement of specific material reconfigurings she refers to as apparatuses.

Apparatuses in themselves can involve both human and non-human bodily arrangements, which shift and intra-act with one another as phenomena. Apparatuses are 'material-discursive' in that they produce meanings and material beings while simultaneously excluding the production of others. Boundaries or cuts within the apparatus According to Barad, the deeply connected way that everything is entangled with everything else means that any act of observation makes a "cut" between what is included and excluded from what is being considered. This cut is a subjective act which depends on context, points of views and apparatus configurations at hand. Thus, throughout the complexity of enactment and agency, boundaries or cuts are not given but constructed [14]. Cuts or boundaries remain temporary and are dependent on the situation at hand. For example, Goodwin [34, p. 20] speaks of the "symbiotic" relationship between gestures and their objects, whereby the gesture's 
objects are integral components of the gesture itself. On the other hand, the actor is also integrally part of the gesture. It becomes somewhat tricky to define the clear cut boundaries between the bodies involved in the gesturing. The integral whole (of gesture, actor and object) becomes more easily understood as a phenomenon. Another example of the shifting nature of boundaries or cuts can be found in Suchman's [33, p. 263-264] description of technology intensive medicine, whereby the transitions of patient anaesthetic states is described, "Over the course of an anaesthesia, agency involved in the maintenance of vital bodily functions are progressively delegated from the patient as an autonomously embodied entity to an intricately interconnected sociomaterial assemblage and then back again".

\subsection{Why Agential Realism?}

Agential realism offers the opportunity for individuals (or groups) who possess and act out embodied tacit knowledge to continue to do so in the presence of communication and information technology, which in turn, act as enhancers of tacit knowledge creation and sharing within the groups or individuals in question. Tacit knowledge remains tacit without attempting to be fully articulated and thus avoids the perilous undertaking of disembodiment. This implies that the body of the bearer must somehow accompany and not be dissociated from the technology in question. That is not to say that the technology cannot carry some of the tacit knowledge in the form of explication. But there will always be a bodily component that cannot be fully explicated and can therefore only be shared with others across intraactions with the body of the bearer. This comes back to Collins [3] and Tsoukas [12] argument of immersion with the individual or group in question - which the addition of non-human objects in the form of technology, thus forming an apparatus made up of individuals (or a group) coupled with technology, which in turn, produces the phenomena of tacit knowledge creation and sharing across intra-actions. Embodied knowledge is now embodied within the total apparatus as opposed to purely human delineations whereby technology becomes an extension of humans thus producing a blurred boundary between humans and technology, and whereby cuts or boundary to be made depend on context, interpretation and configurations at hand. In a sense, we are now looking at cyborgs as opposed to separate human and nonhuman entities. This is exactly what Lucy Suchman [33] in her work on Human-Machine Reconfigurations proposes.
Underpinning Suchman's work is agential realism, whereby she speaks of shifting boundaries which depend on context, points of views and humanmachine configurations (or apparatuses) at hand. Suchman [33] describes technology intensive medicine, involving the transitions of patient anaesthetic states as an example of intra-action occurring between humans and machines. We do not have to go to into the realm of sci-fi to find other examples of cyborgs (ex. mechanical shovel operators, airline pilots, individuals with limb prosthesis, etc.).

Duguid [35, p. 5] explains how Suchman showed that communication between a user and the machine was not, as Xerox "designers assumed, between two comparable intelligences. Ordinary conversation, ethnomethodologists had showed, with its efficient use of linguistic indexicals, its suggestive silences and gestures, its rituals of turn taking, its reliance on contextual resources, and its open-ended trajectory, was extraordinarily complex. In contrast, the idea of "interaction" and "intelligence" embedded (but not embodied) in the machines were remarkably impoverished". Suchman drew a distinction between devices built to execute preordained plans with accuracy and efficiency, and humans who use plans in context and improvisation as one among many guides to action. As Duguid [35, p. 5] argues, "this reconceptualization of the plan presented a profound challenge to the assumptions of AI, Cognitive Science, and Human-Computer Interaction". Of importance, Suchman's [33] work argues that as pre-ordained plans are rigid but context ever changing, intuition, improvisation and interpretation in work are essential rather than unnecessary for deploying a plan. Also reechoing Collin's [3] and Tsoukas [12] incessant warnings on the limits and dangers of trying to completely explicitize tacit knowledge, Duguid [35, p. 7] adds, "implicit assumptions cannot all be made explicit...Practical understanding is more fundamental than detached theoretical understanding ... We do not relate to things through having representations of them...Meaning is fundamentally social, and cannot be reduced to the meaning-giving activity of individual subjects...I cannot imagine Suchman disagreeing with any...also...through Suchman, Heidegger has provided central tools for the critique of AI and Cognitive Science and the general understanding of humanmachine interaction and communication".

\subsection{A few words on critical realism}

Before discussing past and current examples of human-machine configurations which are (or are potentially) in line with an agential realist approach, a few words should be given to a current companion 
approach that is attracting more attention within the study of information systems - namely, critical realism. In critical realism, structures and interactions are two objects of study that mutually shape and inform each other, but that can nonetheless be analytically separated in time [36]. In a recent analysis of agential realism made by both Mutch [37] and Leonardi [38], agential realism's break with the dichotomy established by social constructivism and naïve realism, both of which retain commitments to separatism and representationalism, is seen as being problematic for studying "the combinations of the social and the material" [47, p. 2 and 11], or of examining the "nature" of "material properties" [32, p. 22]. More precisely, agential realism's presumptions of non-separability or entanglement (for example, between action and structure considered as being one in the form of action alone) and non-essentialism ("indeterminacy") make it unsuitable to studying the "impacts" of technology or how technology "inscribes" aspects of social structure [37, p. 22]. Both Mutch [37] and Leonardi [38] use this argument to indicate the contrasting strength of critical realism in this regard, whereby action and structure (in a manner similar to Gidden's structuration theory) are considered as separate or dual entities and as such allows for the opportunity to analyse both structure (which, in borrowing from Cook and Brown [2] is explicit or known) and the role of action (which borrowing from both Polanyi as well as Cook and Brown [2] in terms of 'knowing', is predominantly tacit in nature) and how they imbricate one another [38, p. 73]. In answering this critique, Scott and Orlikowski [39, p. 77-80], argue "Precisely! Agential realism is not useful here. Its ontology is explicitly opposed to viewing the social and material as separate, and assuming that properties and boundaries are inherent. In precluding considerations of separate entities, their combinations, and their inherent properties, agential realism is doing its job...this is not a weakness of agential realism but its strength. By providing an ontological position and theoretical apparatus for examining entanglement and enactment, agential realism offers conceptual and analytical traction for making sense of the world and its possibilities in new ways... Barad's move toward performative alternatives to representationalism shifts the focus from questions of correspondence between descriptions and reality (e.g., do they mirror nature or culture?) to matters of practices, doings, and actions. Practices from this perspective are not tasks undertaken by people in roles, but material-discursive practices enacted through apparatus that simultaneously constitute and organize phenomena... When Mutch does discuss Barad's work (pp. 15-16), it is to offer an outline of a few of her concepts and then criticize them for inadequately dealing with two ideas that are central to critical realism: emergence and stratification, and structure and agency (ibid. p. 12). He then finds - not surprisingly given his starting point - that agential realism does not offer the same resources for addressing these issues as does critical realism. In developing agential realism, Barad's agenda has never been to offer a blueprint for "how to carry out concrete social analysis" (ibid. p. 16). Berating agential realism for supplying "a shaky foundation" to social science (ibid. p. 17) is simply misplaced. Suggesting as much is akin to censuring critical realism for offering a shaky foundation to geological analysis".

While this paper acknowledges that inseparability between structure and action can indeed pose a problem when dealing with the generation and sharing of explicit knowledge and explicit information, we consider agential realism to be a more valid approach when considering the irreducible, embodied and action oriented nature of expert tacit knowledge being produced and shared between individuals within a group (or between groups) in the presence of technology. To distill this tacit knowledge into an explicit form which can stand alone within technology is a fruitless endeavor. Yet technology and humans intra-acting together, we argue may not only maintain tacit knowledge within the group or work environment, but may further enhance its creation and sharing, whereby technology becomes an extension of the human senses and bodily movements either in a real or a virtual sense (ex. simulators).

\subsection{Possible knowledge system configurations?}

One possible configuration already at work which appears to have affinities with the agential realist approach is in freestyle chess, whereby drawing inspiration from Cowen's [40] book Average is Over, freestyle chess players have adopted the centaur approach. Rather than half-horse, half-human, a centaur chess player is one who plays the game by marrying human intuition, improvisation and creativity with a computer's brute-force ability to remember and calculate a staggering number of chess moves, countermoves and outcomes. Teaming the two in chess, experts say, produces a force that plays better chess than either humans or computers can manage on their own.

Of particular interest are current socio-technical expert systems in the health care sector being developed which have evolutive capabilities [41]. Current configurations seem to be more in line with a critical realist stance, whereby users may be able to contact experts within a community of practice (for example, an expert neuro-surgeon within a group, yet 
tacit knowledge may be lost because of the emphasis on transferring knowledge from one expert to another practitioner across explication alone. The challenge here would be on the one hand transmit highly contextual body knowledge (for example, a complex surgical maneuver), across all modes of senses and body movements in question - would a mere film suffice? Exposure across different forms of virtual reproduction? Exposure across remote displacement to the contextual site in question? While we do not pretend to have a complete and one-size-fits-all solution, we argue that technologies which can help trigger bodily senses across real or simulated situatedness (and not just verbal or codified articulation alone), could potentially allow collective tacit knowledge to be shared via imitation and learning by doing. This being said, in line with Leonardi [38], and more specifically stated by Scott and Orlikowski [39, p. 77-80], "one of the more welcome developments in the field [of information systems] over the past decades has been the plurality of theoretical and methodological approaches used...We see no reason why critical realism and agential realism cannot work alongside each other, exploring information systems and organizations phenomena through shared commitments to subtle realism - joining in conversation".

\section{Conclusions}

Past literature has claimed that knowledge systems can enhance or facilitate the creation, retention, transfer and application of tacit knowledge. While this paper agrees that this objective is indeed realizable, it argues that the literature has so far failed to successfully operationalize this, since at the core of their models lies the flawed epistemological assumption of knowledge 'conversion' - or more specifically, tacit to explicit knowledge conversion. This, in turn, manifests itself in the problematic effort of "capturing", "translating" and "converting" tacit knowledge into storable explicit knowledge. This paper has attempted to show that the often misunderstood contextual, personal, subjective, and embodied nature of tacit knowledge within individuals and groups (i.e. distributive) renders it problematic (if not impossible) to wholly reduce into an explicit form.

The alternative epistemology of agential realism is proposed which allows us to reframe tacit knowledge within knowledge systems, whereby humans and machine are coupled together (or intra-act) to enhance and retain tacit knowledge creation and sharing without putting undue emphasis on its conversion and storability into an explicit form - thus, tacit is allowed to 'live and let live' in such a configuration. While words and code can help, they can never fully explicate or address the inherent ineffability of tacit knowledge, for to try to do so is to 'kill it' or make it disappear.

This critical-conceptual paper proposes a few nascent examples of human-machine or knowledge system configurations which have affinities or potential affinities with an agential realist approach. We realize that such examples are highly suggestive and lack adequate empirical justification, but hope that such an approach can serve as a basis for further debate. The authors intend to conduct empirical studies within identified knowledge systems that resemble agential realist configurations.

\section{References}

[1] Nonaka, I. and H. Takeuchi, Hitotsubashi on Knowledge Management, John Wiley and Sons (Asia), Singapore, 2004.

[2] S. Cook, and J.S. Brown, "Bridging Epistemologies: The Generative Dance Between Organizational Knowledge and Organizational Knowing, Organization Science, 10:4, 1999, pp. 381-400.

[3] H. Collins, Tacit and Explicit Knowledge, University of Chicago Press, Chicago, 2010.

[4] D. Leonard, and W. Swap W, "Deep Smarts", Harvard Business Review, 30:2, 2004, pp. 157-169.

[5] H. Collins, "Bicycling on the Moon: Collective Tacit Knowledge and Somatic-limit Tacit Knowledge", Organization Studies, 28:2, 2007, pp. 257-262.

[6] L.H. Friedman and S, Bernell, "The Importance of Team Level Tacit Knowledge and Related Characteristics of HighPerforming Health Care Teams", Health Care Management Review, 31:3, 2006, pp. 223-230.

[7] S. Høyland, K. Aase and J.G. Hollund, "Exploring varieties of knowledge in safe work practices-an ethnographic study of surgical teams", Patient Safety in Patients, 5:21, 2011, pp. 1-7.

[8] M.H. Selamat, and J. Choudrie, "The Diffusion of Tacit Knowledge and its Implications on Information Systems: The Role of Meta-Abilities", Journal of Knowledge Management, 8:2, 2004, pp. 128-139.

[9] L. Falconer, "Organizational Learning, Tacit Information, and e-Learning: A Review", The Learning Organization, 13:2, 2006, pp. 140-151.

[10] M. Alavi, and D.E. Leidner, "Review: Knowledge Management and Knowledge Management Systems: Conceptual Foundations and Research Issues", MIS quarterly, 25:1. 2001, pp. 107-136. 
[11] Nonaka, I. and Takeuchi, H., The Knowledge Creating Company, Oxford University Press, New York, 1995.

[12] Tsoukas, H., "Do we really understand tacit knowledge" in M. Easterby-Smith \& M. Lyles (eds), The Blackwell Handbook of Organizational Learning and Knowledge Management, Blackwell, 2003, pp. 410-427.

[13] Carter, C., S. Clegg and M. Kornberge, A Very Short, Interesting and Reasonably Cheap Book about Studying Strategy, Sage Publications, London, 2008.

[14] Barad, K. Meeting the Universe Halfway: Quantum Physics and the Entanglement of Matter and Meaning, Duke University Press, Durham, NC, 2007.

[15] M. Polanyi, Personal Knowledge: Towards a PostCritical Philosophy. University of Chicago Press, 1958.

[16] M. Polanyi. The Tacit Dimension. London, Routledge. University of Chicago Press, 1966.

[17] Polanyi, M. and Prosch, H. Meaning, Chicago: The University Of Chicago Press, 1975.

[18] Polanyi, M., Personal Knowledge, Chicago: The University of Chicago Press, 1962.

[19] Virtanen, I. "In Search for a Theoretically Firmer Epistemological Foundation for the Relationship Between Tacit and Explicit Knowledge", The Electronic Journal of Knowledge Management, 11(2), 2013, pp118-126.

[20] Nonaka, I., Toyama, R. and Konno, N. "SECI, Ba and Leadership: a Unified Model of Dynamic Knowledge Creation”, Long Range Planning, 33, 2000, pp. 5-34.

[21] Nonaka, I. Toyama, R. and Hirata, T., Managing Flow: A Process Theory of the Knowledge-Based Firm, PalmgraveMacMillan, New York, 2008.

[22] Nonaka, I. and G. von Krogh, "Tacit knowledge and knowledge conversion: Controversy and advancement in organizational knowledge creation theory", Organization Science, 20(3), 2009, pp. 635-652.

[23] Nonaka, I., Kodama, M., Hirose, A. and Kohlbacher, F. "Dynamic fractal organizations for promoting knowledgebased transformation-A new paradigm for organizational theory." European Management Journal, 32(1), 2014, pp. 137-146.

[24] Hall, R. and Andriani, P. 'Managing knowledge associated with innovation', Journal of Business Research, 56, 2003, pp. 145-152.

[25] Oakeshott, M.. Rationalism in Politics and Other Essays, Indianapolis: Liberty Press, New and Expanded Edition, 1991.

[26] Ray, T. and S. Clegg, "Can We Make Sense of Knowledge Management's Tangible Rainbow? A Radical
Constructivist Alternative", Prometheus: Critical Studies in Innovation, 25(2), 2007, pp. 161-185.

[27] Glasersfeld, E. von, Radical Constructivism: A Way of Knowing and Learning, RoutledgeFalmer, London, 2002.

[28] Weick, K., Sensemaking in Organizations, Sage Publications, Thousand Oaks, CA, 1995.

[29] Ribeiro, R. and H. Collins, "The bread-making machine: tacit knowledge and two types of action", Organization Studies, Vol. 28, Issue 9, 2007, pp. 1417-1433.

[30] Merleau-Ponty, M. Trans: Colin Smith. Phenomenology of Perception, London: Routledge \& Kegan Paul, 1962.

[31] Latour, B. , We Have Never Been Modern, Harvard University Press, Cambridge, MA., 1993.

[32] W.J. Orlikowski, "Sociomaterial practices: Exploring technology at work", Organization Studies, 28(9), 2007, pp. 1435-1448.

[33] L.A. Suchman, Human-Machine Reconfigurations: Plans and Situated Actions, Cambridge University Press, Cambridge, 2009.

[34] Goodwinn, C., "The body in action. In Discourse, the Body and Identity", In Coupland, J. and Gwyn, R. (Eds), Palmgrave/MacMillan, New York, 2003, pp. 19-42.

[35] Duguid, P." On rereading. Suchman and Situated Action", Le Libellio d' AEGIS, 8(2), 2012, pp, 3-9.

[36] Archer, Margaret S. Realist Social Theory: The Morphogenetic Approach, Cambridge University Press, New York, 1995.

[37] Mutch, A. "Sociomateriality - taking the wrong turning?", Information and Organization, 2013, 23 (1), pp. $28-40$.

[38] Leonardi, P., "Theoretical foundations for the study of sociomateriality", Information and Organization, 2013, 23 (1), pp. 59-76.

[39] Scott, S.V. and Orlikowski, W., "Sociomateriality taking the wrong turning?: a response to Mutch", Information and Organization, 2013, 23 (2), pp. 77-80.

[40] Cowen, T., Average Is Over: Powering America Beyond the Age of the Great Stagnation, Dutton Adult, 2013.

[41] Flynn, A.J., Shi, W., Fischer, R., Friedman, C.P., "Digital Knowledge Objects and Digital Knowledge Object Clusters: Unit Holdings in a Learning Health System Knowledge Repository", The 49th Hawaii International Conference on Systems Sciences Proceedings, 2016. 